\title{
Ensaios de uma psicologia do trabalho no lazer de aventura
}

\section{Essays of a working psychology in leisure activities of adventure}

\author{
DOI: $10.46814 /$ lajdv3n6-008
}

Recebimento dos originais: 01/10/2021

Aceitação para publicação: 12/11/2021

\section{Marcelo Guidi}

Psicólogo, especialista em psicologia do trabalho pelo Centro de Atividades, Desenvolvimento e Estudos (CADE). Participou como psicólogo de equipe de competitiva de rafting na Universidade do Vale do Paraíba (UNIVAP) e ocupou, durante 5 anos, a função de psicólogo do trabalho na Universidade de Taubaté (UNITAU). Atualmente trabalha no Centro de Psicologia Aplicada (CePA) da Universidade de Taubaté e em consultório particular.

Endereço institucional: Rua Barão de Pedra Negra, 235, Centro, Taubaté, SP. CEP.:12020-2020

E-mail: marcguidi@yahoo.com.br

\section{RESUMO}

O mundo do trabalho se altera a cada dia. Ao prever ou rever um caminho profissional alguns sujeitos podem recorrer às aspirações pessoais (re)organizar o rumo de sua carreira. Esse (re)manejamento profissional pode buscar inspirações nas atividades de lazer onde o prazer e a satisfação funcionam como um empuxo significativo à existência. Esta pesquisa caracterizou o percurso profissional de seis sujeitos que optaram por trabalhar com seu lazer preferido: as práticas de aventura na natureza. Este estudo considerou que as escolhas profissionais são mediadas por fatores políticos, econômicos, sociais e pessoais. Na medida em que se consolidam conceitos, valores, oportunidades e interesses o efeito das experiências de aventura podem permitir uma leitura mais crítica da escolha profissional e oferecer um certo recuo ao modelo hegemônico de trabalho. O lazer de aventura, socialmente instalado como contracultura, pode promover uma identidade "radical" através de valores de exploração, desafio e superação, acentuando um elemento heróico (integrativo/disruptivo) presente também na literatura. Todos os entrevistados definiram o trabalho como fonte de sofrimento, obtendo no lazer algo de uma realização pessoal. Ao enfrentar uma possível dissolução dos paradoxos (semi-lazer) o prazer no trabalho foi obtido pela conversação (saber) e pela prática em si. As condições da economia familiar, as oportunidades do mercado, o network e a capacidade de persistir, foram aspectos importantes na inauguração e manutenção desta trajetória profissional. Entre as dificuldades destacam-se o modelo ultrapassado de gestão de políticas públicas ligadas ao ecoturismo no Brasil, a falta de consenso na conceituação e regulamentação das diversas práticas de aventura na natureza, a sazonalidade das modalidades, o elevado custo e durabilidade dos equipamentos e a reduzida valorização dos profissionais da área. Para os entrevistados, as vivências em aventura promoveram um novo significado ao trabalho. Eles cruzaram o "estreito de Gibraltar" laboral, um mar (de desafios) se abre a sua frente. Reunindo elementos de seus antepassados, o "trabalho hercúleo ou sisífico" exigirá mais que suor e tortura; exigirá uma atualização em sua rede de sentidos: um novo Ulisses para uma nova odisséia.

Palavras chave: trabalho, lazer, aventura, realização pessoal, ecoturismo.

\section{ABSTRACT}

The working world changes every day. By predicting or reviewing a professional way, some subjects can call upon personal aspirations to (re)organize their carrier's direction. Through that professional (re-)examination, it may be possible to find inspirations in leisure activities in which pleasure and 
satisfaction function as a meaningful pushing into existence. This survey has defined the professional trajectory of six subjects who chose to work with their favorite leisure activity: practices of nature adventure. This study has deemed that the professional choices are settled by political, economic, social and personal factors. As the concepts, values, opportunities and interests are consolidated, the effect of the adventure experiences may allow a more critical reading about professional choice and offer a retreatment to the hegemonic pattern of work. The adventure leisure, socially installed as a counterculture, may provide a "radical" identity through values of exploration, challenge and overcoming, and emphasizes a heroic (integrative/disruptive) element existing also in Literature. All the interviewees have defined work as source of suffering, as they obtain some self-fulfillment from leisure. By facing a possible dissolution of paradoxes (semi-leisure), the pleasure at work has been obtained through the conversation (getting knowledge) and the practice itself. The conditions of familiar economy, job opportunities, networking, and persistence capability have been important aspects in this professional trajectory's initiation and maintenance. Among the difficulties, outdated pattern of managing public policies related to ecotourism in Brazil, the absence of agreement of conceptualization and regulation of the various nature adventure practices, seasonality of its modalities, high costs and equipment durability, and professionals' appreciation in this field are pointed. For the interviewees, the adventure experiences ascribed a new meaning to work. They have crossed the workrelated "strait of Gibraltar"; a (challenging) sea is opened in front of them. By uniting elements of their ancestors, "Sisyphean and Herculean work" will demand more than sweat and torture. It will demand an update on its senses network: a new Ulysses for a new Odyssey.

Keywords: work, leisure, adventure, self-fulfillment, ecotourism.

\section{INTRODUÇÃO}

O ano é 2021, a primeira edição do trecho que irá introduzir esse artigo é de 1960, mas a obra de Roy Lewis (1993) remete à idade da pedra lascada. Lascou-se tudo! Estamos numa altura do conto onde a ficção pode nos parecer um tanto familiar. É quando o chefe de uma horda primitiva de homensmacaco, diz: "Grosso modo, calculo que um terço de nosso tempo seja gasto dormindo, um terço procurando caça e o terço restante mastigando a carne obtida. [...] Quando a mera rotina de ganhar a vida nos aprisiona tanto, sobra tempo para refletir?” (p.59). Essas palavras que compõem a ficção de uma era passada nos conduzem ao tema desta pesquisa: Tempo de trabalho e tempo livre. O conto segue até que os homens-macacos descobrem como cozinhar e assar as carnes e isso diminui o tempo da mastigação. É quando o personagem-narrador, Ernest diz: “Agora que comer exigia bem menos tempo, eu dispunha de tempo livre para colocar os pensamentos em ordem. Oswald usava o tempo livre para caçar, e Papai para realizar experiências. Eu devotava meus momentos de lazer a introspecção. [...] Imprevisível e assustador era o mundo exterior, mais imprevisível e assustador ainda o interior” (p.112). Será que trabalho e o lazer são sempre uma questão de tempo?

Parece claro que nenhum sujeito escapa ao seu próprio tempo e Lewis não tem essa intenção, pelo contrário ele brinca com os referenciais modernos para construir uma sátira do homem primitivo. O tempo tripartido (na modernidade: oito horas para dormir, oito horas para trabalhar e oito horas de 
tempo livre) é uma construção histórica determinada pela revolução industrial. Enquanto dormir parece ser uma condição inequívoca, trabalhar e tempo livre não o são. Ou pior, "ser livre” por um tempo já pressupõe que, em outro tempo estivemos “presos!". Assim, somos todos colonizados por perspectivas de alguma época que respondem a sistemas operatórios específicos. Não se trata de fugir a essa colonização, mas entender porque às vezes essas interpretações se estendem (sangram) por demasiado tempo. Geralmente isso acontece quando indagamos sobre: o que é trabalho? A ideia mais imediata relacionada esse fenômeno ainda recupera a sua origem etimológica do latim tripalium, trabicula: instrumento de tortura para empalar rebeldes ou Labor que significa esforço penoso, dobrar-se sob o peso de uma carga, dor, sofrimento, pena e fadiga. Enquanto outros conceitos parecem ser esquecidos ou distorcidos de maneira premeditada, como por exemplo, a origem da palavra lazer que deriva do latim licere e que significa ser lícito ou ócio ou que curiosamente se refere à otium ou scholé que no uso de suas derivações se estende para schola, schule, school, ou seja, lugares de formação e instrução. Uma instrução para a vida e não para o trabalho técnico - essa divisão corrobora com o surgimento das classes sociais (INACIO, 2020).

A psicologia do trabalho aqui subverte a si mesma e nessa pesquisa visa investigar a influência que o lazer ou tempo livre pode ter sobre o próprio trabalho, redirecionando e/ou construindo novas perspectivas de carreira/ofício. Acometido pelo próprio enigma dessa investigação o pesquisado recupera no discurso de dois empresários, um esportista, um explorador e dois vendedores que trabalham com o lazer de aventura, as motivações, dramas e consequências de investir em algo que transforma/transtorna a ideia de laborar.

\section{DESENVOLVIMENTO}

A partir da quase inofensiva posição do lazer, do descanso, da recreação, do ócio, da preguiça, o trabalho foi sendo indagado por sua "natureza peculiar". É natural trabalhar? É natural descansar? Talvez para os organismos vivos não haja muita opção, pois tudo que é vivo precisa manter um esforço mínimo de troca entre interno e externo para sobreviver. A natureza capacita os organismos para que eles possam transformar a matéria disponível em nutrientes necessários a sua sobrevivência e assim atender as suas necessidades metabólicas e sustentar o ciclo da vida. Enquanto algumas criaturas passam todo tempo se alimentando outras fazem-no de modo intermitente. Nessas criaturas o momento de procura, de perseguição e captura, exige um esforço suplementar. Existe um tempo para se alimentar e um tempo de processar. Mas tudo ainda é um tempo biológico: tempo de fome, o tempo da procura, da coleta ou da caça, para enfim, como vimos, o tempo da mastigação, da digestão e da saciedade. Dessa saciedade talvez decorra também algo de uma satisfação, de um tempo de descanso para recuperar as forças envolvidas no esforço suplementar. De certa forma todo ser vivo transforma a 
natureza, produz algo, mas "o animal somente produz sob o imperativo das necessidades físicas imediatas, enquanto que o ser humano produz mesmo quando não possui esse imperativo (INACIO apud MARX, 2020, p.534). Mas as semelhanças tendem a se encerrar por aí quando comparamos o esforço do organismo com o esforço do sujeito, pois a trama armada pelo ser humano em sua perspectiva histórica ganha sempre novos arranjos a cada época.

A própria noção de tempo de trabalho e de tempo de lazer, como apresentamos acima, foi aprimorada por relações sociais de poder que se erguiam no horizonte da era industrial. Uma revolução que marcaria toda a estrutura de uma sociedade acostumada com os tempos da natureza. (BAUMAN, 2001; JASMIN in NOVAES, 2012). Essa nova perspectiva buscou reposicionar o homem diante da natureza, gerando uma pretensa ideia de soberania. O saber "subiu-lhe a cabeça" e em seu propósito mais vil ele supostamente dominou a natureza.

Curiosamente foi sob a mesma insígnia da razão, que o espírito de aventura ganhou lastro e com a ajuda da tecnologia foi se estendendo cada vez mais à população. Se, no início, o acesso à tecnologia se restringia aos primeiros exploradores, muito da ousadia e da criatividade individual fizeram história no percurso original das práticas de aventura na natureza (PEEDOM,2018). Enquanto alguns pretendiam apenas se divertir, aproveitando seus equipamentos para deslizar nas diversas superfícies da natureza (o surf, por exemplo), outros se esforçavam para alcançar lugares inóspitos da terra, em busca de novas rotas de comércio, pesquisa cientifica ou simples intenção de explorar, conquistar e bater recordes. Nenhumas dessas modalidades, diversão ou exploração, escapavam das tramas correspondentes as relações de trabalho da época, mas essa última, parece se apresentar como uma extensão da ideia de trabalho na era industrial. Um "trabalho a mais" depois do expediente na fábrica, mas com outra conotação. Um esforço que parece alimentar outro tipo de necessidade humana; algo que falha no projeto urbano.

"Exploração", palavra curiosa no contexto dessa pesquisa, pois além de seu sentido mais imediato que significa descobrir, também será utilizado como pela crítica da abordagem psicossocial (sócio histórica) como termo que desvela o mecanismo capitalista para esgotar os recursos naturais e humanos em busca do lucro. A exploração capitalista desmata a floresta da subjetividade, utilizando a força de trabalho para fazer nascer uma ideologia produtiva, baseada no excesso, onde somente poucos enriquecem e outros desfalecem. O capitalismo des-mata, des-falece. Ele não mata, não faz falecer, por completo, pois isso seria sua ruína. Essa exploração incide por um esgotamento controlado, um abuso da mão de obra até o limite do esforço. Inicialmente esse limite era apenas físico e exigia tão somente estratégias que pudessem enquadrar e condicionar o corpo (BAUMAN, 2007; GROS in NOVAES, 2012, LAFARGUE apud DE MASI, 2000) Mais tarde, as estratégias precisaram aliciar e conduzir também as mentes dos trabalhadores, fazendo-os acreditar num protótipo social onde a ascensão social 
e financeira pudesse ser justa à todos que se esforçarem o suficiente (meritocracia). O capitalismo jogava com a esperança religiosa e sob a égide de um Deus onipotente, o qual, supostamente, vigiava a moral trabalhista de "seus crentes", elaborando intersecções como: "Deus ajuda a quem cedo madruga!” (WOLFF, JASMIN e CHAUÍ in NOVAES, 2012; CHEMIN, 2003; LAFARGUE, 1999).

Com a ciência de um lado, reestruturando as modalidades de trabalho e com a religião do outro erguendo perspectivas morais do esforço humano e conjugando-as a partir de um bem supremo, que era, servir ao social, essa nova estrutura trabalhista ganha terreno e mantém as mentes sonâmbulas dos trabalhadores submetidas. (FORRESTER, 1997; BAUMAN, 2001).

Talvez seja impossível despertar de todos os processos de alienação a qual são submetidos os trabalhadores, mas, junto a alguns estudiosos (DUMAZEDIER, 1999; PADILHA, 2003; CHEMIN, 2003), também acreditamos que, nenhum sistema é capaz de sobrepujar toda da subversão humana. Nenhum sistema pode controlar ou dirigir a seu modo a condição (in)alienável do ser humano. Assim embora o projeto de massificação funcione, ele falha. E é a preponderância social dessa falha (por seu numero ou intensidade) que poderá determinar o nascimento de outras formas de trabalho. A falha pode atrair simpatizantes de uma geração que por adesão podem provocar a queda ou substituição de antigos para novos valores. A falha, nessa medida, é sempre aquilo que falta (e sempre faltará algo) aos outros. A falha expõe os aspectos incertos de toda convicção que reina como modelo hegemônico de vida social (VLADIMIR in NOVAES, 2012.)

A criação de saídas, em resposta ao o mal-estar decorrente dessas falhas, pode estar especificamente ligada à chance de subjetivar próprio trabalho, ou seja, colocar de si, ou ainda gerar autenticidade em sua produção. Se o reposicionamento diante da escolha profissional, de um lado parte de um desgosto orgânico de alienação, de submissão e invisibilidade social, por outro considera um gosto peculiar. Os participantes desta pesquisa abriram mão de uma posição de status, salários altos e estabilidade para investir nos próprios sonhos, que se resumem em trabalhar naquilo que eles gostam. Eles investiram em transformar seu hobby em trabalho, sua diversão em sustento, ou inadvertidamente seu ócio em osso! O que encontramos a época da pesquisa (2007), talvez hoje já tenha mudado, mas apresenta-se ainda hoje como em maior intensidade sob alguns aspectos (atualização em 2019) momento de prelo (2021). Parece que as atuais gerações estão mais engajadas com uma pauta onde a escolha pelo ofício seja atravessada pela adequação subjetiva. O ganho salarial ou a renda participam como um fator a mais e não como referencia única na escolha de um trabalho. Elementos que, para Dumazedier (1999), definem o lazer como atividade de caráter: liberatório, desinteressado, hedonístico e pessoal, parece que contribuem em diversas frentes para formar um novo tipo de laço com o trabalho. Arriscamos dizer: "trabalho livre". 


\subsection{RESULTADOS}

O que descobrimos entrevistando os praticantes de aventura na natureza desta pesquisa, foi uma necessidade de fugir ao mal estar do trabalho. Um mal-estar multifacetado mas que pode ganhar síntese no elemento objetivo da máquina, como bem coloca Inacio (apud Engels, 2020):

\footnotetext{
“[...] vigiar as máquinas, renovar os fios quebrados, não são atividades que exigem do operário algum esforço do pensamento, contudo, por outro lado, impedem-no de ocupar o seu espírito com outra coisa. Ou seja, a apropriação dos meios produtivos, da ciência e da cultura permite a exploração. Sendo que a limitação de seu conhecimento mutila e reprime o desenvolvimento de suas faculdades criadoras (p.543).
}

Entendemos que algo dessa fuga ou dessa nova escolha se insinua como resultado do lazer emancipatório (que pela reflexão de sua prática altera a posição do sujeito frente ao mundo) em vez, do recorrente, lazer reparatório (que apenas recarrega o sujeito e o reenvia a condição alienante de trabalho) (NOVAES, CICERO, CHAUÍ, JUNIOR in NOVAES, 2012; DE MASI, 2000; GUTIERREZ, 2001; DUMAZEDIER, 1999). Entretanto, sob lentes mais apuradas de análise é possível observar que, embora o lazer de aventura esteja posicionado (em sua versão mais independente, autônoma e profissional) como um movimento de contracultura, ele ainda pode ser relativa o suficiente para sustentar contradições das mais variadas. É isso que dificulta o consenso entre os praticantes. Se considerarmos a forma política como o sujeito se posiciona em sua pratica, podemos sugerir uma forma mais crítica e outra menos crítica. Enquanto a forma acrítica mantém em suspenso a estrutura dominante (lazer reparatório - movimento turístico em geral), a forma mais crítica (praticantes autônomos - movimento dos veteranos e organizações), aparentemente mais louvável, tende a ser mais disruptiva do que integrativa. Como se o elemento crítico fosse tomado por um substrato radical capaz de se opor de forma reacionária a um sistema dominante. É como se, no lazer junto à natureza (no Brasil leia-se "terra de ninguém"), a vivência de uma "liberdade maior" lhes garantisse o exercício de uma autonomia e independência que é rara ou imperceptível no meio urbano. Essa autonomia inadvertidamente pode sugerir "mais controle sobre a situação" e se estender sob uma forma igualmente precipitada (ou até tirânica) de entender e solucionar a complexa relação entre cultura e natureza. Essa convicção, que tende a cindir com as formas dominantes, guarda seu valor positivo por proteger e preservar, mas pode também convulsionar novas formas de extremismo. Ao "sentir-se mais vivo" na natureza toda "espécie de opressão" que percebe (sofre) no meio urbano pode retornar sob o mesmo radicalismo. É quando, por exemplo, ungido por seu privilégio de conquistador o sujeito assume uma posição de "guardião da natureza"; contrapondo-se a qualquer outro ser humano que, não identificado com os mesmos valores, visite o suposto santuário. 
Psicologicamente, talvez isso corresponda a uma necessidade de se contrapor, na mesma altura em o sujeito sente sofrer. A dureza com que se sentem tratados e excluídos, na sociedade de massa, evoca-lhes a mesma atitude (THOREAU, 2018). Defendemos que talvez, em certa medida, a busca recorrente por desafios na natureza, ao mesmo tempo em que emerge como "válvula de escape", instaura, certa repetição (compulsão) que regula (compensa), pelas chances de superação (vitória), um estado de fracasso (derrota social) vivido nas cidades. Esse fracasso, talvez vivido com maior intensidade pelas classes menos favorecidas, corresponda a um estado depreciativo introjetado historicamente. Um insistente estado de culpa, de menos valia, de invisibilidade social, causada pela permanente espoliação da sua força de trabalho que não acha mais sentido somente no valor preponderante do sacrifício social.

Politicamente, essa perspectiva mais radical tem origem no modelo de conservação americano que exclui qualquer forma de interação do humano com a natureza, impedindo que novas formas de convivência possam ser criadas. No Brasil muitos parques foram inaugurados durante a ditadura militar. É óbvio que as áreas de proteção merecem conservação, mas ainda carecem de elementos permeáveis que promovam relações mais inclusivas com os povos nativos e com dinâmicas de visitação (DIEGUES, 1998).

Pela importância que atribuem à aventura, parece lógico que, os participantes, ao reposicionarem seu lazer como trabalho, transfiram algo dessa ideologia ao seu ofício. Aqui cabe o alerta, pois a posição profissional sanciona com um grau de legitimidade maior o saber daquele sujeito naquela atividade e as resultantes disso podem ameaçar e engessar a própria pratica do lazer. Se essa capacitação tende a empoderar o sujeito a ponto de, perigosamente, "inflar seu ego", também é lícito compreender que ele necessita disso para sobreviver aos desafios que se propõe enfrentar. Os graus de adversidades a que eles se expõem exigem habilidades diferentes daquelas que o permitiriam pensar as sutilezas envolvidas ou de refletir sobre o estado da arte na relação com a natureza.

Os participantes que escolheram trabalhar com seu lazer, não tiveram uma rota fácil. As condições de renda da família nuclear, as oportunidades oferecidas pelo mercado de trabalho, as redes sociais estabelecidas dentro da modalidade de aventura (network) e a capacidade de ousar e persistir, foram fatores importantes para iniciar e manter essa trajetória laboral. Se a escolha por um trabalho “diferente", nesses sujeitos, resgata o momento marcante na França, quando os jovens deixam de se submeter às rotinas massacrantes de trabalho para considerar perspectivas que ultrapassassem o ganho salarial e toda garantia estabelecida pelos direitos trabalhistas (VLADIMIR in NOVAES, 2012); nem tudo, as vezes, saiu como planejado. O elemento mais forte, registrado nesta pesquisa, junto aos entrevistados era a possibilidade de fazer trabalho daquilo que se gostava enquanto lazer. Ao se deslocar da referência salarial (com trabalho em multinacionais) e enfrentar uma nova possibilidade de 
profissional na área do lazer; cada qual em sua história de vida teve de enfrentar dificuldades peculiares dentro de sua área de atuação: vendedores tiveram que se adaptar às exigências das lojas e academias (metas, funções de organização e logística de produtos, clientes enfadonhos, etc.); empreendedores tiveram que criar estratégias de gerenciar suas empresas, vender suas expedições; o esportista teve que esforçar-se para atingir e manter uma posição de destaque (superar recordes). Para tanto, todos, tiveram que utilizar a energia de sua paixão (mergulho, montanhismo, escalada, canoagem, aventura, etc.), o apoio familiar e o lastro financeiro como elemento compensatório a quaisquer defasagens que os levassem a uma frustração de seu investimento. A evidência mais forte disso, no discurso dos entrevistados, era marcada por recorrentes retornos a um grupo de significados que tratavam do prazer de praticar ou falar da atividade que eles gostavam. Era visível, embora escamoteado de alguma forma, que este trabalho, gerava tanto ossos quanto quaisquer os outros trabalhos, mas a possibilidade subjetiva de alternar instantes de ócio ligados a realização pessoal na atividade laboral contribuía para suportar o mal-estar decorrente de algumas obrigações. Ao praticar ou falar sobre aquilo que gostavam de fazer (no lazer) o sujeito se sentia mais empoderado de seu ofício. Ele vendia com mais propriedade, respondia com mais especificidade, ganhava autonomia nas negociações com fornecedores e patrocinadores, pois conhecia a abrangência do produto ou serviço (MORIN, 2001; DEJOURS, ABDOUCHELI \& JAYET,1994). Assim, mesmo diante da dificuldade histórica em construir elementos conceituais, ou ainda, em fazer valer a prática de conceitos muito bem elaborados (mas não adaptados as realidades locais), naquilo que, no Brasil, começou a ser definido como ecoturismo (iniciativas da ABETA - Associação Brasileira de Turismo de Aventura), mesmo diante das dificuldades de contribuir e fazer perseverar as iniciativas de organização das diversas modalidades existentes (como foi as extintas: ABEA - Associação Brasileira de Esportes de Aventura ou a BAS Associação Brasileira de Aventura), mesmo diante da falta de consenso na criação de padrões que regulamentem a qualidade dos serviços para promover um mercado de aventura, mesmo diante da falta de investimento das cidades em infraestrutura para facilitar os acessos turísticos as práticas (ALDRIGUI; CRUZ, 2018), mesmo diante de um cenário econômico flutuante e desfavorável (índices de crescimento de $20 \%$ sofreram queda a partir do seu ápice nos anos noventa), mesmo diante da sazonalidade dos esportes de aventura (ligado as estações do ano); mesmo diante da durabilidade dos equipamentos (a qualidade implica segurança e isso incide sobre a baixa de retorno para novas aquisições) e mesmo diante da banalização profissional (a dificuldade de se profissionalizar na área pois muitos realizam o "trabalho" de graça, pois a alienam-se na diversão) eles heroicamente se mantiveram trabalhando de seu lazer, ou como dizem os estudiosos da sociologia do lazer, mantiveram seu semi-lazer (BRASIL, 2005, 2010 e 2011; DUMAZEDIER, 1999). 
Quando pelo trabalho, o sujeito é mobilizado a enfrentar um “mercado selvagem”, esse é um aspecto onde profissional e aventureiro se encontram. A capacidade de resistir às intempéries sejam eles na natureza ou no mercado de trabalho são habilidades aparentemente transferíveis e corresponde a pragmática explorada pelos treinamentos experienciais ao ar livre, entretanto essa associação, a meu ver, apresenta um valor significativo àqueles que por algum motivo foram "picados pelo bichinho da aventura" ou dizendo de outra forma, orientam-se pelas resultantes do espírito de aventura. Quando as associações se afastam dessa referência a probabilidade de um fracasso ou sucesso momentâneo, aumentam.

\section{CONSIDERAÇÕES FINAIS}

Diante do exposto e, atualizadas algumas considerações, observa-se com mais clareza o percurso que se deu pelos participantes em busca de outra posição laboral. Justamente uma passagem, um equivalente ao "estreito de Gibraltar", que desafia qualquer pessoa a se articular de um modelo de trabalho a outro, onde gostos e interesses pessoais rearticulam valores e conceitos gerando um novo tipo de sujeito. Essa mudança não afeta a todos do mesmo modo, mas resguardados os efeitos da maior ou menor radicalidade, de alguma forma eles colocam de si no trabalho a partir do lazer, e ousaram diminuir os paradoxos entre esses fenômenos. Exercitaram um resgate de si mesmos do submundo do trabalho, buscando realizar outros sentidos do existir (CAMPOS, 2020). Para além daquilo que se constatou nessa empreitada, seriam necessárias outras pesquisas para avançar sobre as sutilezas e as armadilhas dessa nova posição; pois tais conseqüências só a história revelará como o tempo. Entretanto, sob uma perspectiva literária, talvez a arte, antecipando-se ao seu tempo, nos encaminhe a algum lugar.

Tragédia, pecado, culpa, redenção, condenação, compulsão, trabalho, sofrimento, enganação, preguiça, ócio, lazer, obstinação, aventura, malícia, amor, são significados presentes nas mais antigas histórias de aventura. E é lá onde essa arte nasce que, desde então, ela imita a vida. Por essa via arriscamos dizer que o "trabalho hercúleo" junto com o mito de Sísifo (símbolo do trabalho repetitivo e sem sentido) se junta com a Odisséia de Homero onde Ulisses é resgatado pelo protótipo do homem da era industrial, forte, vigoroso, resistente. Mas Ulisses não acaba em Homero. Na "Divina Comédia" de Dante Alighieri, Ulisses reaparece. Ele está pagando por seus pecados no inferno (pelo estratagema do cavalo de Tróia) e conta que não lhe bastou retornar para casa depois de suas jornadas (de aventuratrabalho). Nem a segurança do lar, nem a companhia de sua esposa de seus filhos ou o apreço por seu pai, foram suficientes para lhe firmar as raízes em seu reino. Ele diz que algo de seus percursos o capturou e lançou seu desejo de volta ao mar. Diz ele que "era um fervor que o impelia a conhecer o mundo e dos homens os vícios e valor”. Ele não soube dizer pelo que foi fisgado, mas o ímpeto de retornar era-lhe forte demais para que ele recuasse. Ele então navegou até o extremo dos mares do 
ocidente. Lá ele ultrapassou as colunas de Hércules (atual estreito de Gibraltar) que se erguiam como fronteira do desconhecido. Sua curiosidade entoa sua motivação "Não fosses feitos para viver tão bruto, mas para buscar virtude e sapiência”. Era o anúncio da próxima era, a era dos descobrimentos onde no século XV e XVI o mundo se voltou para a exploração. No duplo sentido da palavra o paraíso foi corrompido pela ganância e pelo poder. E aquilo que poderia ser reeditado de outra forma, continuou a multiplicar-se com espólio e abuso mercantil.

Por muito tempo apenas alguns valores de Ulisses foram acentuados enquanto outros foram esquecidos. Foi somente pelas mãos do escritor James Joyce, no século XX que o personagem Ulisses repactua o laço com sua jornada. O tempo é compacto. A aventura de anos se reduz a um dia, expondo elementos que dariam vertigem ao mais hábil dos marinheiros. Estamos em outro terreno, o terreno da linguagem, dos sentidos produzidos na jornada que não se firmam, que se equivocam, que assumem um modelo de bricolagem. Não há sentido fixo. Impera o manejo com a diversidade dos valores e dos desejos (CALLIGARIS, 2017; OLIVEIRA 2013; THOREAU, 2018, FORRESTER, 1997). A convicção heróica serve a alguns momentos, mas não em todos. Principalmente, quando é preciso lidar com a adversidade das opiniões que hoje se multiplicam a todo instante. A maneira "militar" de conquistar o trabalho, ou a natureza, em alguns casos já não é mais suficiente. Hoje, com a pósmodernidade, essa conquista é deposta em sua funcionalidade, ganhando cada vez mais a perspectiva ética e estética além dos elementos ligados ao jogo e à diversão. Para, além disso, outros aspectos filosóficos fazem avançar o desenvolvimento desse herói, que não mais se sustenta em apenas vencer, mas também em recuar, desistir e finalmente renunciar ao seu bem maior.

Em algumas profissões não há mais limites rígidos entre trabalho e lazer. A pandemia e os esforços do home office vem a consagrar o teletrabalho. Mais do que uma mudança na estrutura de trabalho e de lazer, o desafio atual e fazer conviver com diferentes formas de organização dos tempos, das atividades e dos afetos ligados a tudo isso. $\mathrm{O}$ modelo patriarcal se dissolve e o mundo se torna líquido. Até o recipiente onde se adicionam os sentidos é experimental, insipiente; porque a pergunta fundamental, não é mais “o que eu vou ser quando crescer?”, mas, algo como: “será que vou crescer enquanto ser?

A crise dos valores não deixou os aventureiros desempregados, pois o laço e a paixão por suas práticas continuam reverberando sua ousadia, sua coragem, seu poder de enfrentamento. O que se anuncia de novo, não está mais a vista de seus olhos, não são mais só as montanhas nevadas, os oceanos longínquos, os desertos inexplorados, a savana selvagem, são o sentido que se produz em todos esses locais "de trabalho", sem a demagogia da era industrial que tudo quis transformar em lucro. O dinheiro está em crise. E como disse Thoreau (2018): “O preço de qualquer coisa é a quantidade de vida que você troca por isso". E a vida hoje já não se confina sobre o mesmo propósito de antes. 


\section{REFERÊNCIAS}

ADVENTURE SPORT FAIR. Disponível em: http://www.adventurefair.com.br. Acessado em 13 jan. 2008.

ALDRIGUI, M. Políticas públicas de Turismo no Brasil: Reflexões sobre a Realidade Brasileira. In: SEMINÁRIO INTERNACIONAL POLÍTICAS PÚBLICAS, PATRIMONIALIZAÇÃO, TURISMO E SOCIEDADE, 2018, São Paulo. Anais eletrônicos.São Paulo, USP, 2018. Disponível em: <https://www.youtube.com/watch?v=fR_z_Kti96w>. Acesso em: 30 nov. 2018, 4:00:15.

ASSOCIAÇÃO BRASILEIRA DAS EMPRESAS DE TURISMO DE AVENTURA - ABETA. Disponível em: <http://www.abeta.com.br>. Acessado em: 07 jan. 2008.

AURÉLIO, A. B. H. Novo Dicionário da Língua Portuguesa. 4.ed. Curitiba, Positivo, 2009.

BAUMAN, Z. Modernidade Líquida. Rio de Janeiro, Jorge Zahar, 2001. Cap. 4.

A Vida Fragmentada: Ensaios sobre a Moral Pós-Moderna. Lisboa, Relógio D’Água, 2007. BORGES, L. O. e YAMAMOTO, O.H. O Mundo do Trabalho. In: ZANELLI, J. C.; ANDRADEBORGES, J. E.; BASTOS, A. V. B. (Org.). Psicologia, organizações e trabalho no Brasil. Porto Alegre, Artmed, 2004. p.24-62.

BRASIL, Ministério do Turismo. Regulamentação, normalização e certificação em turismo de aventura. Relatório diagnóstico. Brasília, Ministério do Turismo, 2005.

.Turismo de Aventura: orientações básicas. Brasília, Ministério do Turismo, 2006a 3.ed. Brasília, Ministério do Turismo, 2010a.

BRASIL, Ministério do Turismo; ABETA, Associação Brasileira das Empresas de Ecoturismo e Turismo de Aventura. Planejamento estratégico para o segmento de Turismo de Aventura. Belo Horizonte, ABETA, 2006b.

.Perfil do turista de aventura e do ecoturista no Brasil. São Paulo, ABETA, 2010b.

Programa Aventura Segura: concepção, metodologia e resultados. Belo Horizonte, Ed. dos autores, 2011.

BRUHNS, H. T. e MARINHO, A. (Org.).Turismo, Lazer e Natureza.São Paulo, Manole, 2003.

CAMPOS, D. C. Ser feliz, é tudo que se quer: saúde do trabalhador e precarização do trabalho. Latin American Journal of Development. Curitiba, jan./fev. 2020, v.3, n.1.

CHEMIN, B. F. O lazer como produto do trabalho. In: MÜLLER, A. e DACOSTA, L. P. (Org.). Lazer e Trabalho: um único ou múltiplos olhares? Santa Cruz do Sul, EDUNISC, 2003.

CÍCERO, T. Elogio ao Ócio. Filosofia: ciência \& vida. São Paulo, Escala, n. 12, p.16-23, 2007.

CODO, W. Identidade e economia (I): espelhamento, pertencimento, individualidade (2002). In: CODO, W. Por uma psicologia do trabalho: ensaios recolhidos. São Paulo, Casa do Psicólogo, 2006 . 
Um diagnóstico do trabalho - em busca de prazer. In: CODO, W. Por uma psicologia do trabalho: ensaios recolhidos. São Paulo, Casa do Psicólogo, $2006 \mathrm{~b}$.

COSTA, V. L. de M. e FERREIRA, N. T. Ciências Humanas e Imaginário Social. In: (Org.).

Esporte, Jogo e Imaginário Social. Rio de Janeiro, Shape, 2003.

CRUZ, R. C. A. Políticas públicas de Turismo no Brasil: Reflexões sobre a Realidade Brasileira. In: SEMINÁRIO INTERNACIONAL POLÍTICAS PÚBLICAS, PATRIMONIALIZAÇÃO, TURISMO E SOCIEDADE, 2018, São Paulo. Anais eletrônicos.São Paulo, USP, 2018. Disponível em: <https://www.youtube.com/watch?v=fR_z_Kti96w>. Acesso em: 30 nov. 2018, 4:00:15.

DEJOURS, C.; ABDOUCHELI, E. e JAYET, C. Psicodinâmica do Trabalho: Contribuições da Escola Dejouriana à Análise de Relação Prazer, Sofrimento e Trabalho.São Paulo, Atlas, 1994.

DE MASI, D. O ócio criativo. 2.ed. Rio de Janeiro, Sextante, 2000.

DIEGUES, A. C. O mito moderno da natureza intocada. 2.ed. São Paulo, Hucitec, 1998.

DUMAZEDIER, J. Sociologia empírica do lazer. 2.ed.São Paulo, Perspectiva, SESC, 1999.

GUTIERREZ, G. L. Lazer e Prazer. Campinas, Autores Associados, 2001.

ICMbio. Parques do Brasil: visitar é proteger! Estratégias de implementação da visitação em unidades de conservação federais: prioridades de execução 2018-2020. Coordenação Geral de Uso Público e Negócios, 2018.

INACIO, A.A.; ALMEIDA, T.M.G.; MEZAROBBA, G. Educação e trabalho: a formação de consenso na sociedade sob a influencia do capital. Latin American Journal of Development. Curitiba, nov./dez. 2020, v.2, n.6.

KONDER, L. O que é dialética. 23.ed. São Paulo, Brasiliense, 1992.

LA BOETIE, E. Discurso sobre a servidão voluntária. São Paulo, Martin Claret, 2009.

LAFARGUE, P. O direito à preguiça.São Paulo, Hucitec, UNESP, 1999.

LEWIS, R. Porque almocei meu pai. 3.ed. São Paulo, Companhia das Letras, 1993.

MINAYO, M. C. S. Pesquisa Social: teoria, método e criatividade. Petrópolis, Vozes, 1994.

MORIN, E. M. Os sentidos do trabalho. Revista de Administração de Empresas. São Paulo, v.41, n.3, p.8-19, jul./set. $2001 . \quad$ Dísponível em: <http://www.poprh.com.br/clientes/poprh/adm/arquivos/arqs/arq\%5B10\%5D\%5B1\%5D.pdf >. Acessado em: 15 mai. 2008.

MORIN, E. M.; TONELLI, M. J.; PLIOPAS, A. L. V. O trabalho e seus sentidos. Revista Psicologia e Sociedade. São Paulo, v.19, n.1, p.47-56, 2007. Número especial. Dísponível em: $<$ http://www.scielo.br/scielo.php?script=sci_arttext\&pid=S0102-

$71822007000400008 \& \operatorname{lng}=$ en\&nrm=iso\&tlng=pt>. Acessado em 15 mai. 2008. 
MÜLLER, A. Cultura do lazer do trabahador da indústria: inclus̃̃o ou exclusão? In: MULLLER, A. e

MULLER, A. Cultura do lazer do trabalhador da indústria: inclusão ou exclusão? In: MÜLLER, A. e DACOSTA, L. P. (Org.). Lazer e Trabalho: um único ou múltiplos olhares? Santa Cruz do Sul, EDUNISC, 2003.

NOVAES, A. Mutações: Elogio a preguiça. São Paulo, Edições SESC SP, 2012.

OLIVEIRA, F. (Coord.) Penélope e Ulisses. Associação Portuguesa de Estudos Clássicos. Coimbra, 2003. Disponível em: https://classicadigitalia.uc.pt/pt-pt/livro/penélope_e_ulisses. Acessado em: 10 out. 2019.

PADILHA, V. Se o trabalho é doença, o lazer é remédio? In: MÜLLER, A. e DACOSTA, L. P. (Org.). Lazer e Trabalho: um único ou múltiplos olhares? Santa Cruz do Sul, EDUNISC, 2003.

PEEDOM, J. Montain. Documentário sobre montanhas. Austrália, 2017. Disponível em: <https://www.netflix.com/watch/80221498?trackId=13752289\&tctx=0\%2C0\%2C2c844c50d8d1005 5a28cbf5ffbb77de611da2265\%3Aa8f6b2136c27a900e4dbac06e93e68f3be9c4e26\%2C\%2C>. Acessado em: 16 dez. 2018.

PEREIRA, D. W. e ARMBRUST, I. Pedagogia da Aventura: os esportes radicais, de aventura e de ação na escola. Jundiaí, Fontoura, 2010.

ROMANINI, V. e UMEDA, M. Esportes de Aventura ao seu alcance. São Paulo, BEI, 2002.

ROTTERDAM, E. Elogio da Loucura. São Paulo, Lafonte, 2017.

SCHMIDT, J. Dicionário de Mitologia Grega e Romana. Lisboa, Edições 70, 1985.

SIQUEIRA, M. M. M. e JÚNIOR, S. G. Vínculos do Indivíduo com o Trabalho e com a Organização. In: ZANELLI, J. C.; ANDRADE-BORGES, J. E.; BASTOS, A. V. B. (Org.). Psicologia, organizações e trabalho no Brasil. Porto Alegre, Artmed, 2004.

THOREAU, H. D. Walden. Porto Alegre, L\&PM, 2018. 